\title{
A Comparative Study of Modified Materials of Acetylcholinesterase Biosensor
}

\author{
Xia Sun ${ }^{1}$, Xiangyou Wang ${ }^{1}{ }^{*}$, Wenping Zhao ${ }^{1}$, Shuyuan $\mathrm{Du}^{1}$, \\ Qingqing $\mathrm{Li}^{1}$, and Xiangbo $\mathrm{Han}^{2}$ \\ ${ }^{1}$ School of Agricultural and Food Engineering, Shandong University of Technology, \\ ${ }^{2}$ College of Computer Science and Technology, Shandong University of Technology, \\ Zibo 255049, Shandong Province, P.R. China \\ wxy@sdut. edu.cn
}

\begin{abstract}
In this study, multi-walled carbon nanotubes (MWCNTs), gold nanoparticles (GNPs) and Prussian Blue (PB) were used for modifying glassy carbon working electrode (GCE) to construct acetylcholinesterase (AChE) biosensor respectively. Chitosan membrane was used for immobilizing $\mathrm{AChE}$ through glutaraldehyde cross-linking attachment to recognize pesticides selectively. Before the detection, the enzyme membrane was quickly fixed on the surfaces of modified electrode with O-ring to prepare an ampero-metric acetylcholinesterase biosensor for organophosphate pesticides. The fabrication procedures were characterized by cyclic voltammetry and amperometric i-t curve. The electrochemical behaviours of three modified sensors were compared, and the results showed that AChE-PB/GCE possessed higher oxidation peak current at a lower potential. Based on the inhibition of organophosphorus pesticides to the enzymatic activity of AChE, using dichlorvos as model compound, the sensitivity of three modified biosensors were compared, the results showed that the detection limit of AChE-PB/ GCE was lowest.
\end{abstract}

Keywords: Biosensor; Acetylcholinesterase; Pesticide residue; Modified electrode.

\section{Introduction}

Organophosphorus (OP) pesticides are widely used in agricultural production which leads to the most important environmental pollutants. Moreover, OP compounds inhibit acetylcholinasterase (AChE) that hydrolyses the neurotransmitter acetylcholine (ACh), often causing severe impairment of nerve functions of human or even death.[13] For these reasons, the development of rapid and efficient monitoring methods is very important. In the past years, many studies have focused on biosensors based on the enzymatic inhibition by the OP pesticides. They have the additional advantage of simplicity, rapidity, reliability, low cost devices and on site monitoring.[4] Generally speaking, the concentration of pesticides is monitored by measuring the change of oxidation current of thiocholine before and after exporsured to pesticides.[5-7]

\footnotetext{
${ }^{*}$ Corresponding author.
} 
However, the oxidation generally requires high potential value on a suitable electrode.[8] In order to enhance the test sensitivity, decrease potential values and the electrochemical interference of other oxidable compounds, the use of some modified materials and methods have gained enormous attention in biosensor technology in recent years, such as multi-walled carbon nanotubes(MWNTs),[9-11] prussian blue (PB)[7,12-13] and gold nanoparticles(GNPs).[14-16] Most of these methods rely on enzyme immobilization directly onto the electrode surface, which cannot overcome the biofouling of the electrode surface, and would eventually lead to the deactivation of the biosensor or at least to worsening of the electrochemical response. Our previous investigation results have shown that using a replaceable membrane as support for the enzyme immobilization has many advantages, for example, enzyme membrane can be easily replaced when enzyme's activity is lost.[9,17] Moreover, there are multiple options for analyte detection based on enzyme immobilization on the membrane (one electrode-multiple membranes-multiple enzymes).[18]

This present work is a continuation of our previous investigations and focused on the comparative study of three modified (MWCNTs, GNPs and PB) materials to obtain higher sensitivity and stability biosensor for OP pesticides. The fabrication procedure was characterized by cyclic voltammograms and amperometric i-t curve, respectively. The electrochemical behaviours of three modified sensors and no modified AChE/GCE sensor were compared, and the results showed that the AChE$\mathrm{PB} / \mathrm{GCE}$ obtained higher oxidation peak current at a lower work potential. Using dichlorvos as model compound, the sensitivity of three modified biosensors were compared, the results showed that the detection limit of AChE-PB/GCE was lowest. The AChE-PB/GCE biosensor exhibited good reproducibi-lity, stability and it was suitable for trace detection of OP pesticide residue.

\section{Experimental}

\subsection{Apparatus}

Cyclic voltammograms and amperometric i-t curve were performed with CHI660D electrochemical workstation (Shanghai Chenhua Co., China). $10 \mathrm{ml}$ of electrochemical cell was made in our laboratory. The working electrode was glassy carbon electrode $(\mathrm{d}=3 \mathrm{~mm})$ or modified glassy carbon electrode. A saturated calomel electrode (SCE) and platinum electrode were used as referenceand auxiliary electrodes, respectively.

\subsection{Reagents}

Acetylcholinesterase was purchased from Nuoyawei Biology Tech.Co. (Shanghai, China). Acetylthiocholine iodide (ATChI), glutaraldehyde $(25 \%)$ and bovine serum albumin (BSA) were provided by Sigma. Cellulose nitrate microporous membrane was purchased from Hangzhou Rikang purification equipment co.,ltd (Hangzhou, China). Chitosan (95\% deacetylation), phosphate buffer (PBS, pH 8.0) and other reagents were all of analytical grade. Dichlorvos was standard product. All the other chemicals were of analytical grade. Distilled water was used throughout for the preparation of solutions. 


\subsection{Preparation of AChE Biosensors}

\subsubsection{Preparation of Chitosan Membrane}

A solution was prepared with $0.1 \mathrm{~g}$ chitosan added to $10 \mathrm{ml}$ of acetate solution (1\%, mass ratio), and the mixture was centrifuged for $5 \mathrm{~min}$ in high-speed centrifuge at $3000 \mathrm{rpm}$ to remove insoluble particles. Finally, the pretreated cellulose nitrate microporous membrane was immersed in this sol for $12 \mathrm{~h}$, and then immersed in phosphate buffer (PBS, $0.1 \mathrm{~mol} / \mathrm{l}, \mathrm{pH}$ 8.0) for $12 \mathrm{~h}$, dried and stored for use.[19]

\subsubsection{The AChE Immobilization}

A solution of $100 \mu \mathrm{l}$ of AChE liquid $(100 \mathrm{U} / \mathrm{ml}), 30.0 \mu \mathrm{l}$ of BSA (1.0\%), $10 \mu \mathrm{l}$ of glutaraldehyde $(5.0 \%)$, and $360 \mu \mathrm{l}$ of PBS $(0.1 \mathrm{~mol} / \mathrm{l}, \mathrm{pH} 8.0)$ were mixed in a $1 \mathrm{ml}$ of centrifuge tube. A chitosan membrane was immersed in it for $8 \mathrm{~h}$ at $4^{\circ} \mathrm{C}$. Finally, enzyme membranes was washed with PBS (0.1mol/l, pH8.0), immersed in PBS $(0.1 \mathrm{~mol} / 1, \mathrm{pH} 8.0)$, and stored at $4^{\circ} \mathrm{C}$ before use.[17]

\subsubsection{Electrode Modification}

(1) The preparation of MWCNTs/GCE

$20 \mu \mathrm{L}$ of mixture of MWNTs, chitosan and glutaraldehyde were covered on a pretreated GCE with final contents of $0.12 \%(\mathrm{w} / \mathrm{v}), 0.48 \%(\mathrm{w} / \mathrm{v})$ and $0.47 \%(\mathrm{v} / \mathrm{v})$ respectively, and allowed for reaction at room temperature for $4 \mathrm{~h}$. After being washed thoroughly with double distilled water, the obtained modified electrode was stored at $4^{\circ} \mathrm{C}$ before use. [20]

(2) The preparation of AuNPs /GCE

$0.01 \% \mathrm{HAuCl} 4$ solution was heated to boiling, and quickly added $1 \mathrm{ml} 1 \%$ sodium citrate. After $1 \mathrm{~min}$, the color of solution changed from yellowish to light rose red. Then the AuNPs solutions were stored in dark glass bottles at $4^{\circ} \mathrm{C}$. After the working electrode was immersed in $10 \mathrm{ml}$ of AuNPs solutions for $24 \mathrm{~h}$ at $4^{\circ} \mathrm{C}$, the surface of working electrode was rinsed in double-distilled water for use.[21]

(3) The preparation of $\mathrm{PB} / \mathrm{GCE}$

A solution was a mixture of $2 \mathrm{mM} \mathrm{K} 3[\mathrm{Fe}(\mathrm{CN}) 6], 2 \mathrm{mM} \mathrm{FeCl} 3,0.1 \mathrm{M} \mathrm{KCl}$, and 10 $\mathrm{mM} \mathrm{HCl}$, and the $\mathrm{B}$ solution was a mixture of $0.1 \mathrm{M} \mathrm{KCl}$ and $10 \mathrm{mM} \mathrm{HCl}$. First, a potential of $+0.4 \mathrm{~V}$ was applied to the electrode in solution $\mathrm{A}$ for $60 \mathrm{~s}$ and then the electrode was transferred to solution $\mathrm{B}$, and scanned by cyclic voltammetry from -0.05 and $0.35 \mathrm{~V}$ at a rate of $50 \mathrm{mV} / \mathrm{s}$ for 12 times. The electrode surface was rinsed with double-distilled water. Finally, the electrode was stored at room temperature.[22]

\subsection{Electrochemical Detection of Pesticide}

The biosensor was tested with amperometric i-t curve (i-t) at a potential of $600 \mathrm{mV}$ versus saturated calomel electrode (SCE). After $100 \mu \mathrm{L}$ of ATChI $(15 \mathrm{mg} / \mathrm{ml})$ solution was injected into the cell, and the peak current was recorded as $\mathrm{I}_{0}$. The cell was washed with distilled water between measurements.

For OP pesticide detection, the pretreated biosensor was first incubated in a given concentration of dichlorvos for $10 \mathrm{~min}$, then it was transferred to the electrochemical cell of $10 \mathrm{~mL}$ PBS $(0.1 \mathrm{~mol} / \mathrm{L}$, pH8.0), and $100 \mu \mathrm{L}$ of ATChI $(15 \mathrm{mg} / \mathrm{mL})$ was injected 
after the current stabilized. The peak current was recorded as $I_{1}$. The inhibition of pesticides was calculated as follows:

$$
I \%=\left(I_{0}-I_{1}\right) / I_{0} \times 100 \%
$$

Where $I \%$ was the degree of inhibition related to the inhibitor concentration. $\mathrm{I}_{0}$ was the initial current of the biosensor which was measured without inhibitor in PBS $(0.1 \mathrm{~mol} / \mathrm{L}, \mathrm{pH} 8.0)$. $\mathrm{I}_{1}$ was the current after the incubation in the PBS $(0.1 \mathrm{~mol} / \mathrm{L}$, pH8.0) with different concentrations of inhibitor.

\section{Result and Discussion}

\subsection{Electrochemical Behavior of AChE-MWCNTs/GCE, AChE-AuNPs/GCE and AChE-PB/GCE}

Fig.1 showed the cyclic voltammograms of AChE-MWCNTs/GCE, AChEAuNPs/GCE and AChE-PB /GCE in the presence of ATChI $(15 \mathrm{mg} / \mathrm{ml})$ in PBS $(\mathrm{pH}$ $8.0)$ at a scan rate of $100 \mathrm{mV} / \mathrm{s}$. After $100 \mu \mathrm{l}$ of ATChI $(15 \mathrm{mg} / \mathrm{ml})$ was injected into PBS, AChE-GNPs/GCE identified an oxidation peak current of $45 \mu \mathrm{A}$ at $510 \mathrm{mV}$, and the AChE-MWCNTs/GCE obtained an oxidation peak current of $22 \mu \mathrm{A}$ at $600 \mathrm{mV}$, and the AChE-PB/GCE was an oxidation peak current of $90 \mu \mathrm{A}$ at $570 \mathrm{mV}$ respectively. The oxidation peak (curve $\mathrm{a}, \mathrm{b}$ and $\mathrm{c}$ ) came from the oxidation of thiocholine, hydrolysis product of ATChI, catalyzed by immobilized AChE. Fig.1 also showed that this peak current of AChE-PB/GCE (curve c) was much higher compared with AChE-MWCNTs /GCE and AChE-AuNPs/GCE. The phenomena was due to PB possess better electrocatalytic ability on the AChE. Whereas, the potential of AChEAuNPs/GCE shifted negatively compared with AChE-MWCNTs/GCE (curve a) and AChE-PB/GCE (curve c). It was likely because that AuNPs possessed inherent high electricity conducting ability, thus can provide a conductive pathway for electron

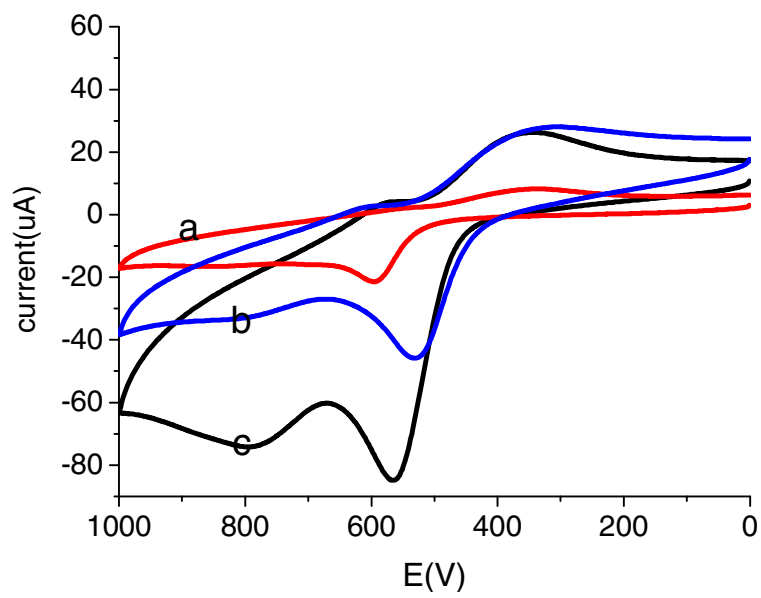

Fig. 1. Cyclic voltammograms of enzyme biosensor modified. MWCNTs modified (a); GNPs modified (b); PB modified (c) in pH 8.0 PBS containing $100 \mu \mathrm{L}$ of ATChI $(15 \mathrm{mg} / \mathrm{mL})$. Scan rate: $100 \mathrm{mV} / \mathrm{s}$. 
transfer and promote electrocatalysis reactions at a lower potential. At the same time, these three modified biosensor obtained oxidation peak current were comparable with that reported electrochemical biosensor at the same potential.[23-24] For this main reason were the use of chitosan membrane, which provided a biocompatible microenvironment around the enzyme molecule to stabilize its biological activity and prevented the enzyme leaking out from chitosan membrane effectively. Dual-layer membranes had synergistic effects towards enzymatic catalysis, thus, the oxidation peak current increased, which can improve detection sensitivity.

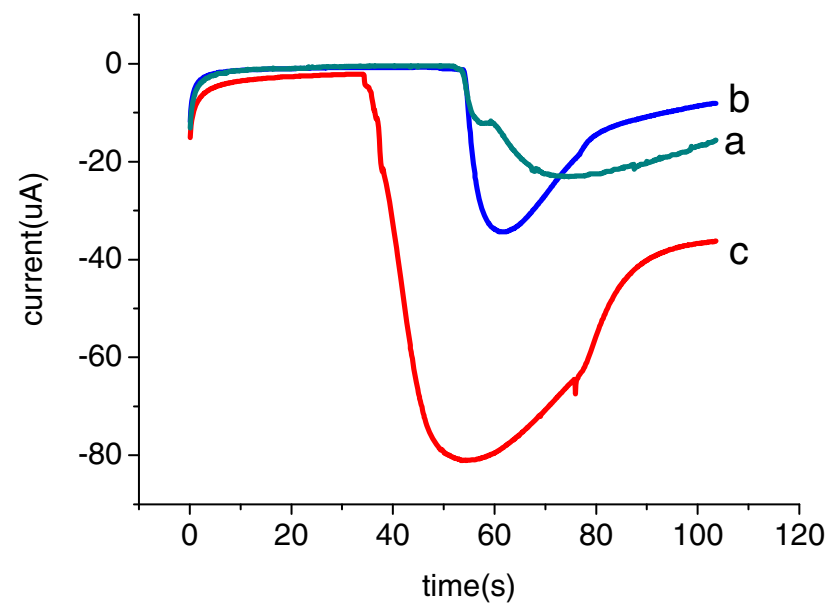

Fig. 2. Amperometric i-t curve of enzyme biosensor modified. MWCNTs modified (a); GNPs modified (b); PB modified (c) in PBS (0.1mol/L, pH8.0) after injected $100 \mu \mathrm{L}$ of ATChI $(15 \mathrm{mg} / \mathrm{mL})$

The current produced by AChE-MWCNTs/GCE, AChE-AuNPs/GCE and AChE$\mathrm{PB} / \mathrm{GCE}$ catalyzing ATChI achieved to $22 \mu \mathrm{A}, 35 \mu \mathrm{A}$ and $80 \mu \mathrm{A}$ at $600 \mathrm{mV}$ repectively (Fig.1), which were according with the result tested by ampomeretric i-t (Fig.2), which indicated that we can also detect electrochemical behavior of enzyme biosensor with ampomeretric i-t.

\subsection{Effect of Phosphate Buffer pH on AChE-MWCNTs/GCE, AChE-AuNPs/GCE and AChE-PB/GCE}

The effect of phosphate buffer $\mathrm{pH}$ value on the peak currents was shown in Fig.3. The current response of three modified biosensors increased with an increase of $\mathrm{pH}$ value up to 7.5, and then the AChE-MWCNTs /GCE current decreased at higher $\mathrm{pH}$ value, whereas, the current of AChE-AuNPs/GCE and AChE-PB/GCE continue increase until $\mathrm{pH}$ value arrive to 8.0. It could be concluded that the values of the peak current of biosensors changed with the different $\mathrm{pH}$ in the range of 5.0 to 8.5. Obviously, the maximum response of peak current appeared at $\mathrm{pH} 7.5$ about AChE-MWCNTs/GCE, and the others at $\mathrm{pH}$ 8.0. The phenomena was due to the $\mathrm{pH}$ value of electrolyte, which had great influence on the activity of enzyme, which led to the change of the anodic peak current at these biosensors. 


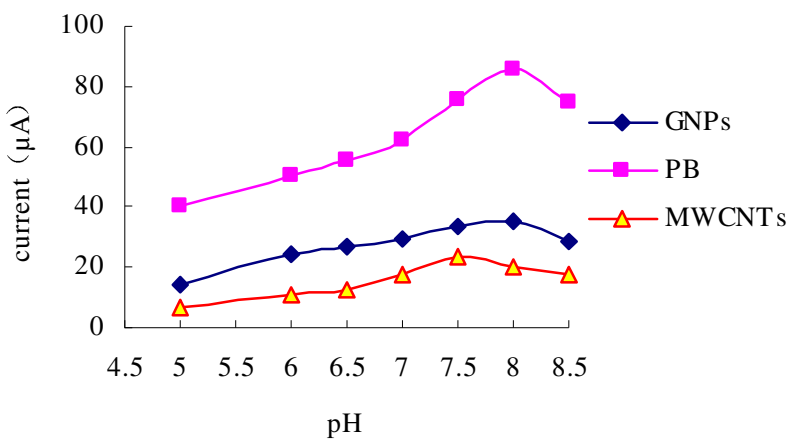

Fig. 3.The influence of $\mathrm{pH}$ on the peak current of enzyme biosensor modified with MWCNTs, GNPs and PB respectively

\subsection{Effect of ATChI Concentration on AChE-MWCNTs /GCE, AChE-AuNPs /GCE and AChE-PB/GCE}

Fig.4. showed the effect of different ATChI concentration on anodic peak current of AChE-MWCNTs/GCE, AChE-AuNPs/GCE and AChE-PB/ GCE. The peak current all increase when the ATChI concentration was less than $15 \mathrm{mg} / \mathrm{l}$, whereas the peak current have no change with further the increasing of the concentration of ATChI. It was likely because that the velocity of enzyme catalyzing substrate reaches to the equilibrium when the substrate added to some concentration, so subsequent increased the substrate concentration, the velocity of enzyme catalyzing substrate did not increase. In this work, the ATChI concentration of $15 \mathrm{mg} / \mathrm{l}$ was selected.

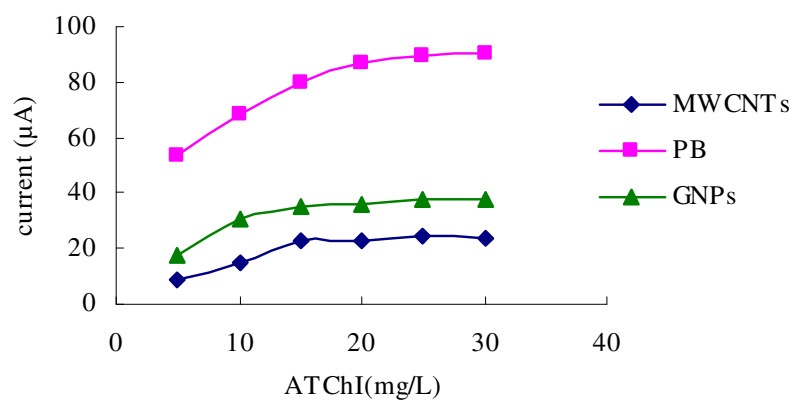

Fig. 4. The influence of ATChI concentration on the peak current of enzyme biosensor modified with MWCNTs, GNPs and PB respectively

\subsection{Effect of Incubation Time on Inhibition}

As shown in Fig.5, OP pesticides displayed increasing inhibition to AChE with incubated time. When the incubated time was longer than $10 \mathrm{~min}$ the three curves all trended to maintain a stable value, which indicated that the binding interaction with active target groups in enzyme could reach saturation. This change tendency of the 


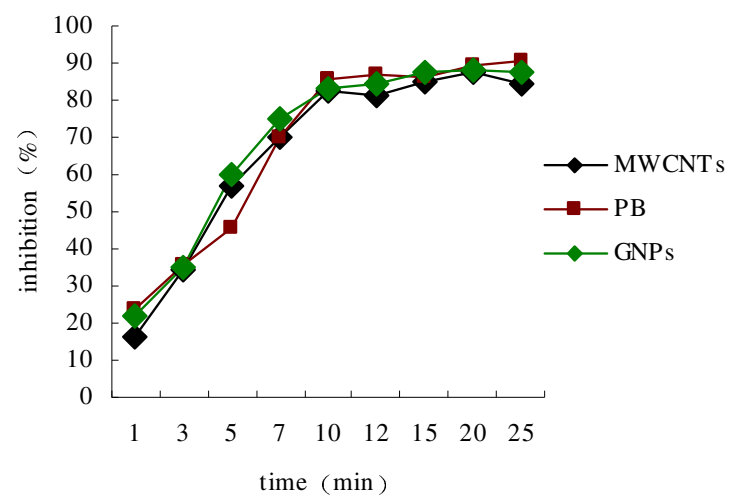

Fig. 5. The influence of Pesticide inhibition time on the peak current of enzyme biosensor modified with MWCNTs, GNPs and PB respectively

peak current value showed the alteration of enzymatic activity, which resulted in the change of the interactions with its substrate. In this work, the three biosensors optimum incubation time of 10 min was selected.

\subsection{Determination of Pesticides}

After AChE-MWCNTs/GCE, AChE-AuNPs/GCE and AChE-PB/GCE were incubated in the standard solution of dichlorvos at a certain concentration for $10 \mathrm{~min}$ respectively, the inhibition rate (calculated by the change of peak current) of these three modified biosensors and the logarithm of dichlorvos concentration all had a certain linear relationship in some range. The detection limit and linear range of AChEMWCNTs/GCE and AChE-AuNPs/GCE were shown in Tab.1. The results showed that the detection limit of AChE-PB/GCE was lowest. The phenomena were indicated that the electrode modified materials played an important role on the sensitivity of enzyme biosensor.

Table 1. The detection limit of three modified biosensors of dichlorvos pesticides

\begin{tabular}{lllcl}
\hline modified biosensor & linear range & $\begin{array}{l}\text { equation of linear } \\
\text { regression }\end{array}$ & $\begin{array}{l}\text { equation } \\
\text { linear regression }\end{array}$ & $\begin{array}{l}\text { of } \\
\text { limit }\end{array}$ \\
\hline $\mathrm{AChE}-\mathrm{PB} / \mathrm{GCE}$ & $10 \mathrm{ng} / \mathrm{l} \sim 10 \mu \mathrm{g} / \mathrm{l}$ & $\mathrm{I}=32.3 \operatorname{lgc}-10.9$ & 0.9968 & $2.5 \mathrm{ng} / 1$ \\
\hline $\mathrm{AChE}-\mathrm{GNPS} / \mathrm{GCE}$ & $50 \mathrm{ng} / \mathrm{l} \sim 10 \mu \mathrm{g} / \mathrm{l}$ & $\mathrm{I}=22.804 \mathrm{lgc}-6.3489$ & 0.9928 & $30 \mathrm{ng} / 1$ \\
\hline $\mathrm{AChE}-\mathrm{MWCNTs} / \mathrm{GCE}$ & $5 \mu \mathrm{g} / \mathrm{l} 50 \mu \mathrm{g} / \mathrm{l}$ & $\mathrm{I}=48.853 \operatorname{lgc}+10.927$ & 0.9921 & $1 \mathrm{ug} / 1$ \\
\hline
\end{tabular}

\subsection{Precision of Measurements and Stability of Biosensor}

The precision intra-assay of the three biosensors was evaluated by assaying three enzyme membranes on the same electrode for ten replicate determinations after exposure to a certain concentration pesticides respectively. Similarly, the inter-assay precision was estimated by assaying three enzyme membranes on six different electrodes. The average relative standard deviation (R.S.D.) of intra-assay and inter-assay were 
found to be 5.1 and $4.27 \%$ of AChE-MWCNTs/GCE, 5.2 and 3.1\% of AChEAuNPs/GCE and 4.8 and $3.5 \%$ of AChE-PB/GCE respectively, which indicated these three modified biosensors are all acceptable re-producibility.

\section{Conclusion}

In this paper, three materials modified have been used for the fabrication of amperometric AChE biosensors. These AChE biosensors all introduce the chitosan membrane to immobilize $\mathrm{AChE}$, the results have shown that chitosan membrane prevent leakage of the enzmye, improve the activity of immobilization enzyme, and can immobilize sufficient amount of AChE. The fabrication procedures have been characterized by cyclic voltammetry and amperometric i-t curve. The electrochemical behaviours of three modified sensor have been compared, and the results showed that AChE-PB/GCE possess higher oxidation peak current at a lower potential. Using dichlorvos as model compound, the sensitivity of three modified biosensors have been compared, the detection limit of AChE-PB/GCE is lowest. This study indicates we can improve the sensitivity of enzyme biosensor by the selection of the modified materials of electrode and realize the trace detection of OP pesticide residue.

Acknowledgments. This work was supported by the National Natural Science Foundation of China (No.30972055), Scientific and Technological Project of Shandong Province (No.2008GG10009027), and the Natural Science Foundation of Shandong Province (No. Q2008D03).

\section{References}

1. Laschi, S., Ogończyk, D., Palchetti, I., Mascini, M.: Enzym. Microb. Technol. 40, 485489 (2007)

2. Ivanov, A.N., Lukachova, L.V., Evtugyn, G.A., Karyakina, E.E., Kiseleva, S.G., Budnikov, H.C., Orlov, A.V., Karpacheva, G.P., Karyakin, A.A.: Bioelectrochem. 55, 75-77 (2002)

3. Du, D., Chen, S.Z., Cai, J., Zhang, A.D.: Biosens. Bioelectron. 23, 130-134 (2007)

4. Arduini, F., Ricci, F., Tuta, C.S., Moscone, D., Amine, A., Palleschi, G.: Anal. Chim. Acta. 58, 155-162 (2006)

5. Ramírez, G.V., Fournier, D., Silva, M.T.R., Marty, J.L.: Talanta. 74, 741-746 (2008)

6. Wu, H.Z., Lee, Y.C., Lin, T.K., Shih, H.C., Chang, F.L., Lin, H.P.: J. Taiwan Institute Chem. Eng. 40, 113-122 (2009)

7. Pchelintsev, N.A., Vakurov, A., Millner, P.A.: Sens. Actuators B 138, 461-466 (2009)

8. Pingarrón, J.M., Sedeño, P.Y., Cortés, A.G.: Electrochimica Acta 53, 5848-5866 (2008)

9. Sun, X., Wang, X., Zhao, W.: Sensor. Lett. 8, 247-252 (2010)

10. Ivanov, Y., Marinov, I., Gabrovska, K., Dimcheva, N., Godjevargova, T.: J. Mol. Catal. B: Enzym. 63, 141-148 (2010)

11. Chen, J., Du, D., Yan, F., Ju, H.X., Lian, H.Z.: Chemistry A European Journal 11, 1467$1472(2005)$

12. Li, J.P., Wei, X.P., Yuan, Y.H.: Sens. Actuators B 139, 400-406 (2009)

13. Sun, X., Wang, X.: Biosens. Bioelectron 25, 2611-2614 (2010) 
14. Du, D., Chen, S.Z., Song, D.D., Li, H.B., Chen, X.: Biosens. Bioelectron. 2, 475-479 (2008)

15. Kim, G.Y., Shim, J., Kang, M.S., Moon, S.H.: J. Hazard. Mater. 156, 141-147 (2008)

16. Shulga, O., Kirchhoff, J.R.: Electrochem. Commun. 9, 935-940 (2007)

17. Sun, X., Wang, X.Y., Liu, Z.: Int. J. Food Eng. 4, 4 (2008)

18. Marinov, I., Gabrovska, K., Velichkova, J., Godjevargova, T.: Int. J. Biol. Macromol. 44, 338-345 (2009)

19. Qiang, Z., Chen, Y., Guo, H., Liu, J.: J. Dong Hua Univ. 33, 212-215 (2007)

20. Du, D., Huang, X., Cai, J., Zhang, A.D., Ding, J.W., Chen, S.Z.: Analytical and Bioanalytical Chemistry 387, 1059-1065 (2007)

21. Agüí, L., Peña-Farfal, C., Yáñez-Sedeño, P., Pingarrón, J.M.: Talanta. 74, 412-420 (2007)

22. Jin, G., Hu, X.: Chinese Journal of Analysis Laboratory 27, 14-17 (2008)

23. Wu, H.Z., Lee, Y.C., Lin, T.K., Shih, H.C., Chang, F.L., Lin, H.P.P.: J. Taiwan Institute Chem. Eng. 40, 113-122 (2009)

24. Yin, H.S., Ai, S.Y., Xu, J., Shi, W.J., Zhu, L.S.: J. Electroanal. Chem. 637, 21-27 (2009) 